with $4 / 6$ functionalities and 6/17 of resources reaching consensus in VR2.

Conclusions A consensus process was used to determine consensus for functionalities and resources needed to support CCCare-P. Most standard inclusions (e.g. disease activity indices) were non-contentious and thus minimally influenced by the consensus process. Conversely, complex items (e.g. mental health assessments) were markedly more influenced.

\section{IDDF2021-ABS-0075 ANALYTICAL AND CLINICAL PERFORMANCE OF AUTOMATED IMMUNOTURBIDIMETRIC ASSAY FOR DETECTING FECAL CALPROTECTIN}

${ }^{1}$ Tieshan Wang ${ }^{*},{ }^{2}$ Haiyun Shi. 'Clinical Laboratory Center, Beijing Friendship Hospital, Capital Medical University, China; ${ }^{2}$ Department of Gastroenterology, Beijing Friendship Hospital, Capital Medical University, National Clinical Research Center for Digestive Disease, China

\subsection{6/gutjpl-2021-IDDF.128}

Background The purpose is to evaluate the ability of a new automated immunoturbidimetric assay for detecting fecal calprotectin(FC), to compare its analytical and clinical diagnostic performance with ELISA assay, and to analyze whether it is suitable for distinguishing the severity of intestinal inflammation.

Methods According to the clinical diagnosis, 413 patients were divided into two groups: mild inflammation group(MIG), including normal control, polyps, irritable bowel syndrome and non-progressive adenoma; severe inflammation group (SIG), including progressive adenoma, Crohn's disease, ulcerative colitis and cancer. Each patient's fecal samples were tested for calprotectin by turbidimetric immunoassay and ELISA. The FC results are calculated and compared.

Results The data range of turbidimetric immunoassay was 0$3500 \mu \mathrm{g} / \mathrm{g}$ feces, while that of ELISA was $0-4500 \mu \mathrm{g} / \mathrm{g}$ feces. There were 141 cases in MIG and 272 cases in SIG. The mean concentration of feces calprotectin in MIG was significantly lower than that in SIG $(\mathrm{P}<0.01)$ (IDDF2021-ABS0075 Figure 1). Passing bablok regression showed that there

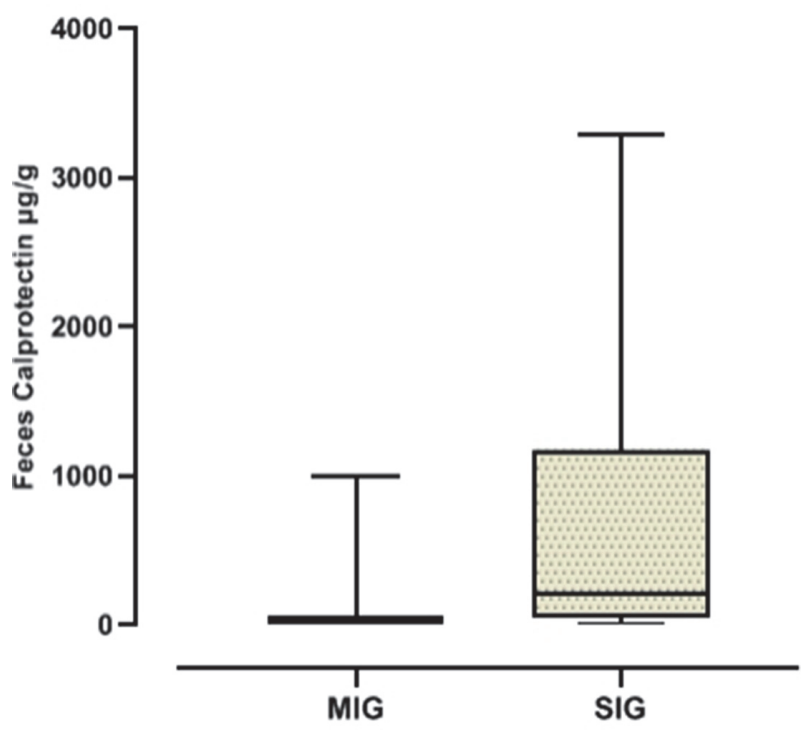

Abstract IDDF2021-ABS-0075 Figure 1

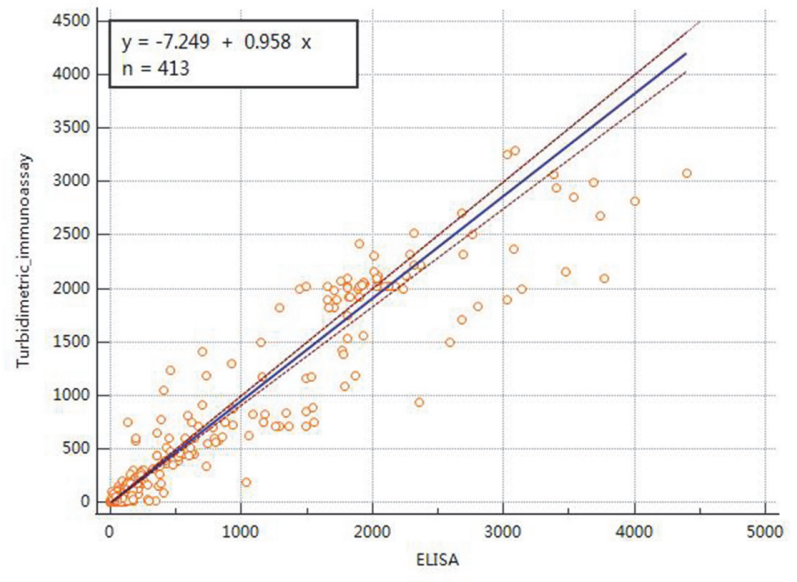

Abstract IDDF2021-ABS-0075 Figure 2

\begin{tabular}{llllll}
\multicolumn{6}{l}{ Abstract IDDF2021-ABS-0075 Table 1} \\
\hline Cut-off $\mu \mathrm{g} / \mathrm{g}$ feces & $\begin{array}{l}\text { Sensitivity } \% \\
95 \% \mathrm{Cl}\end{array}$ & $\begin{array}{l}\text { Specificity } \% \\
95 \% \mathrm{Cl}\end{array}$ & $\begin{array}{l}\mathrm{LR} \\
95 \% \mathrm{Cl}\end{array}$ & $\begin{array}{l}\mathrm{PPV} \% \\
95 \% \mathrm{Cl}\end{array}$ & $\begin{array}{l}\mathrm{NPV} \% \\
95 \% \mathrm{Cl}\end{array}$ \\
\hline 49.90 & 81.99 & 79.43 & 3.99 & 88.5 & 69.6 \\
& $(76.9-86.4)$ & $(71.8-85.8)$ & $(2.9-5.5)$ & $(84.7-91.4)$ & $(63.6-74.9)$ \\
94.19 & 70.22 & 95.74 & 16.5 & 97.0 & 62.5 \\
& $(64.4-75.6)$ & $(91.0-98.4)$ & $(7.5-36.2)$ & $(93.5-98.6)$ & $(58.1-66.7)$ \\
\hline
\end{tabular}

was a good correlation between the two methods (IDDF2021ABS-0075 Figure 2). At the $50 \mathrm{mg} / \mathrm{kg}$ cut-off value of turbidimetric immunoassay manufacturer's guides, the sensitivity of $82.0 \%$ (95\%CI $: 76.8 \%$ to $86.3 \%$ ) and specificity of $80.1 \%$ (95\%CI: $72.4 \%$ to $86.2 \%$ ) could be calculated, and the PPV was $88.8 \% \quad(95 \% \mathrm{CI}: 84.1 \%$ to $92.3 \%)$ and the NPV was $69.8 \%(95 \%$ CI $: 62.0 \%$ to $76.6 \%)$. When the cut-off value was increased, the PPV increased but the sensitivity decreased, and it was not suitable for screening test (IDDF2021-ABS-0075 Table 1).

Conclusions We found immuno turbidimetric assay showed good analytical performance compared with ELISA for detection of fecal calprotectin. The immuno turbidimetric assay also showed good clinical performance being suitable for detecting severe intestinal inflammatory diseases, and had a shorter measuring time which made it suitable for laboratories with a high throughput of samples.

\section{IDDF2021-ABS-0081 DETECTION OF HELICOBACTER PYLORI CAGA, VACA, ICEA VIRULENCE GENES IN PATIENTS WITH GASTRIC CANCER}

${ }^{1}$ Hung Tran Viet*, ${ }^{2}$ Anh Tran Ngoc, ${ }^{3}$ Duat Nguyen Quang, ${ }^{3}$ Huy Duong Quang, ${ }^{4}$ Ha Hoang Thi Thu, ${ }^{5}$ Phu Tran Van. 'Gastroenterology and Hepatology Center, Bach Mai Hospital, Vietnam; ${ }^{2}$ Hanoi Medical University, Vietnam; ${ }^{3}$ Department of Gastroenterology, Military Hospital 103, Military Medical University, Vietnam; ${ }^{4}$ National Institute of Hygiene and Epidemiology, Vietnam; ${ }^{5}$ Vietnam University of Traditional Medicine, Vietnam

\subsection{6/gutjnl-2021-IDDF.129}

Background Helicobacter pylori ( $\mathrm{H}$. pylori) infection causes chronic gastritis, peptic ulcer, gastric cancer and MALT-lymphoma. The association between genotypes of $\mathrm{H}$. pylori and 
Abstract IDDF2021-ABS-0081 Table 1 Primes for PCR

\begin{tabular}{|c|c|c|c|c|}
\hline Gene & Primer designation & Primer sequence & Product (bp) Size of PCR & Heat cycle \\
\hline \multirow[t]{2}{*}{ CagA } & Cag5c-F & 5'-GTTGATAACGCTGTCGCTTC-3' & 350 & $940 \mathrm{C} / 3 \mathrm{~m}$ \\
\hline & Cag3c-R & 5'-GGGTTGTATGATATTTTCCATAA-3 & & \\
\hline VacA & VAG-F & 5'-CAATCTGTCCAATCAAGCGAG-3' & $567 / 642$ & {$[940 \mathrm{C} / 1 \mathrm{~m}, 550 \mathrm{C} / 1 \mathrm{~m}, 72 \mathrm{oC} / 1 \mathrm{p}] \times 40$ cycle } \\
\hline$M 1 / m 2$ & VAG-R & 5'-GCGTCAAAATAATTCCAAGG-3' & & $72 \mathrm{oC} / 10 \mathrm{~m}$ \\
\hline \multirow[t]{2}{*}{ VacA s1/s2 } & VAl-F & 5'-ATGGAAATACAACAAACACAC-3' & $259 / 286$ & \\
\hline & VAI-R & 5'-CTGCTTGAATGCGCCAAAC-3' & & \\
\hline \multirow[t]{5}{*}{ iceA1F iceA1 R } & 5'-GRGRRRRRAACCAAAGTATC-3' & 247 & iсеA1/2 & $950 \mathrm{C} / 5 \mathrm{~m}$ \\
\hline & 5'-CTATAGCCASTYTCTTTGCA-3' & & & [95oc/30s, 48C/45s, $720 \mathrm{C} / 45 \mathrm{~s}]$ \\
\hline & & & & $x$ \\
\hline & & & & 35 cycle \\
\hline & & & & $720 \mathrm{C} / 10 \mathrm{~m}$ \\
\hline \multirow[t]{2}{*}{ iceA2 F iceA2 R } & 5'-GTTGGGTATATCACAATTTAT-3' & 229 & & \\
\hline & 5'-TTRCCCTATTTTCTAGTAGGT-3' & & & \\
\hline
\end{tabular}

Abstract IDDF2021-ABS-0081 Table 2 Rate of H. pylori CagA gene in the group of patients with gastric cancer and gastritis

\begin{tabular}{lllllll}
\hline Group & Gastric cancer & \multicolumn{3}{c}{ Gastritis } & \multicolumn{3}{c}{ OR 95\%Cl } & P \\
\cline { 2 - 5 } Gene & Quantity (n) & Rate (\%) & Quantity (n) & Rate (\%) & \\
\hline CagA+ & 65 & 71,4 & 43 & 46,7 & 2,8 & 0,01 \\
CagA- & 26 & 28,6 & 49 & 53,3 & $(1,5-5,2)$ & \\
Total & 91 & 100 & 92 & 100 & & \\
\hline
\end{tabular}

Abstract IDDF2021-ABS-0081 Table 3 Rate of H. pylori vacA gene in the group of patients with gastric cancer and gastritis

\begin{tabular}{lllllll}
\hline \multirow{2}{*}{$\begin{array}{l}\text { Group } \\
\text { Gene }\end{array}$} & \multicolumn{2}{l}{ Gastric cancer } & \multicolumn{3}{c}{ Gastritis } & \multicolumn{3}{c}{ OR 95\%Cl } & P \\
\cline { 2 - 5 } & Quantity (n) & Rate (\%) & Quantity (n) & Rate (\%) & \\
\hline VacA+ & 78 & 85,7 & 46 & 50 & 6,0 & $<0,05$ \\
VacA- & 13 & 14,3 & 46 & 50 & $(2,9-12,2)$ & \\
Total & 91 & 100 & 92 & 100 & & \\
\hline
\end{tabular}

Abstract IDDF2021-ABS-0081 Table 4 The allele types of $\mathrm{H}$. pylori with vacA gene in two groups.

\begin{tabular}{llllll}
\hline \multirow{2}{*}{ Gene VacA } & \multicolumn{2}{l}{ Gastric cancer } & \multicolumn{3}{l}{ Gastric cancer } \\
\cline { 2 - 5 } & Quantity (n) & Rate (\%) & Quantity (n) & Rate (\%) & \\
\hline $\boldsymbol{s 1}(+)$ & 34 & 37,4 & 32 & 34,8 & 0,716 \\
$(-)$ & 57 & 62,6 & 60 & 65,2 & \\
s2 (+) & 45 & 49,5 & 18 & 19,6 & 0,0001 \\
$(-)$ & 46 & 50,5 & 74 & 80,4 & \\
m1 (+) & 37 & 40,7 & 30 & 32,6 & 0,258 \\
$(-)$ & 54 & 59,3 & 62 & 67,4 & \\
m2 (+) & 40 & 44,0 & 19 & 20,7 & 0,01 \\
$(-)$ & 51 & 56,0 & 73 & 79,3 & \\
\hline
\end{tabular}

gastric cancer remains controversial. The aim of this study was: To investigate the $\mathrm{H}$. pylori vacA alleles, iceA and cagA in patients with gastric cancer.
Abstract IDDF2021-ABS-0081 Table 5 Relative risk of patients infected with $\mathrm{H}$. pylori iceA genotype A1.

\begin{tabular}{lll}
\hline Group IceA1 & Gastric cancer $(\mathbf{n}, \%)$ & Gastritis $(\mathbf{n}, \%)$ \\
\hline iceA1 (-) & $41(45.0)$ & $73(79.3)$ \\
iceA1 (+) & $50(55.0)$ & $19(20.7)$ \\
\hline
\end{tabular}

$\mathrm{OR}=4.685,95 \% \mathrm{Cl}:[2.332-9.532]$

Abstract IDDF2021-ABS-0081 Table 6 Relative risk of patients infected with $\mathrm{H}$. pylori iceA genotype $\mathrm{A} 2$.

\begin{tabular}{lll}
\hline Group IceA1 & Gastric cancer $(n, \%)$ & Gastritis $(n, \%)$ \\
\hline iceA2 (-) & $81(89.0)$ & $85(92.4)$ \\
iceA2 (+) & $10(11.0)$ & $7(7.6)$ \\
\hline
\end{tabular}

Abstract IDDF2021-ABS-0081 Table 7 Relative risk of patients infected with $\mathrm{H}$. pylori iceA + .

\begin{tabular}{lll}
\hline Group IceA & Gastric cancer $(\mathbf{n}, \%)$ & Gastritis $(\mathbf{n}, \%)$ \\
\hline iceA (-) & $34(37.4)$ & $66(71.7)$ \\
iceA (+) & $57(62.6)$ & $26(28.3)$ \\
\hline
\end{tabular}

Methods 91 patients with gastric cancer and 92 chronic gastritis were enrolled in this study. We obtained biopsy specimens from the stomach at the tumor margin in patients with gastric cancer, and from the antrum of stomach in patients with chronic gastritis. DNA extraction and polymerase chain reaction were used to detect the presence or absence of cagA, assess the polymorphism of $v a c A$ and iceA. Primers for PCR is presented in IDDF2021-ABS-0081 Table 1.

Results A total of 183 patients (gastric cancer: 91 and chronic gastritis: 92) were found to have both positive urease test results and biopsy specimens from patients with chronic gastritis and gastric cancer. We found positive cagA $(65 / 91,71.4 \%)$ (IDDF2021-ABS-0081 Table 2), vacA (78/91, 85.7\%) (IDDF2021-ABS-0081 Table 3), $m 1$ (37/91, 40.7\%), $m 2$ (40/ 92, 44\%), s1 (34/91, 37.4\%), s2 (45/91, 49.5\%) (IDDF2021- 
ABS-0081 Table 4), iceA (57/91,62.6\%) (Table 7) and iceAl (50/91, 55\%) (IDDF2021-ABS-0081 Table 5), iceA2 (10/91, 11\%) (IDDF2021-ABS-0081 Table 6) strains in patients with gastric cancer. The odds of gastric cancer in $\mathrm{H}$. pylori with iceA was 4.245 higher than those who did not carry iceA (IDDF2021-ABS-0081 Table 7). The odds of gastric cancer in H. pylori with iceA1 was 4.685 higher than those who did not carry iceA1 (IDDF2021-ABS-0081 Table 5).

Conclusions VacA s1, $\mathrm{m} 2$, and iceA are predominant in patients with gastric cancer. As compared with those in non-cancer patients, patients with gastric cancer have less vacA $s 1$ and more $\mathrm{m} 1$ subtypes. The odds of gastric cancer in $\mathrm{H}$. pylori with iceA was 4.245 higher than those who did not carry iceA. The odds of gastric cancer in $\mathrm{H}$. pylori with iceA1 was 4.685 higher than those who did not carry iceA1.

\section{IDDF2021-ABS-0082 APPLICATION AND LEARNING CURVE OF NICE CLASSIFICATION FOR COLORECTAL POLYPS UNDER NON-MAGNIFYING ENDOSCOPY}

XianHua Zhuo*, Yi Lu, Jiachen Sun. Department of Gastrointestinal Endoscopy, The Sixth Affiliated Hospital, Sun Yat-Sen University, China

\subsection{6/gutjnl-2021-IDDF.130}

Background To study the application value of narrow-band image international colorectal endoscopic (NICE) classification under non-magnifying endoscopy in the accuracy of colorectal polyp judgment and clarify the learning curve of NICE classification application of endoscopes with different experiences

Methods 1674 pictures of colorectal polyps from the Sixth Affiliated Hospital of Sun Yat-sen University from December 2019 to April 2020 were collected. Three junior physicians and one senior physician were respectively used for NICE classification. Pathological diagnosis was taken as the gold standard, and the accuracy rate was calculated and the learning curve was drawn

Results The accuracy of NICE classification was $88 \%$ and $95.6 \%$, respectively, for primary and senior physicians. The accuracy rates of primary and senior physicians in the diagnosis of inflammatory hyperplasia and invasive cancer were $87.4 \%$ and $84 \%, 99.2 \%$, and $100 \%$, respectively, with no statistically significant difference $(\mathrm{P}>0.05)$. The accuracy of adenoma and early cancer was $63.2 \%$ and $90.7 \%$, respectively, with a statistically significant difference $(\mathrm{P}<0.05)$ (IDDF2021ABS-0082 Table 1). The Kappa values of the preliminary and senior physicians for the detection of the consistency between NICE typing and pathological results were 0.8 and 0.93, respectively. After 900 and 350 images of colorectal polyps were observed by primary and senior physicians, the accuracy of judgment was nearly $100 \%$ and the fluctuation was reduced (IDDF2021-ABS-0082 Figure 1. Learning curve of NICE for primary and senior doctors)

Conclusions The overall accuracy of NICE classification for colorectal polyps under non-magnifying endoscopy is high, and endoscopists can achieve high accuracy after learning and accumulating a certain number of endoscopic images, which is easy for clinical promotion
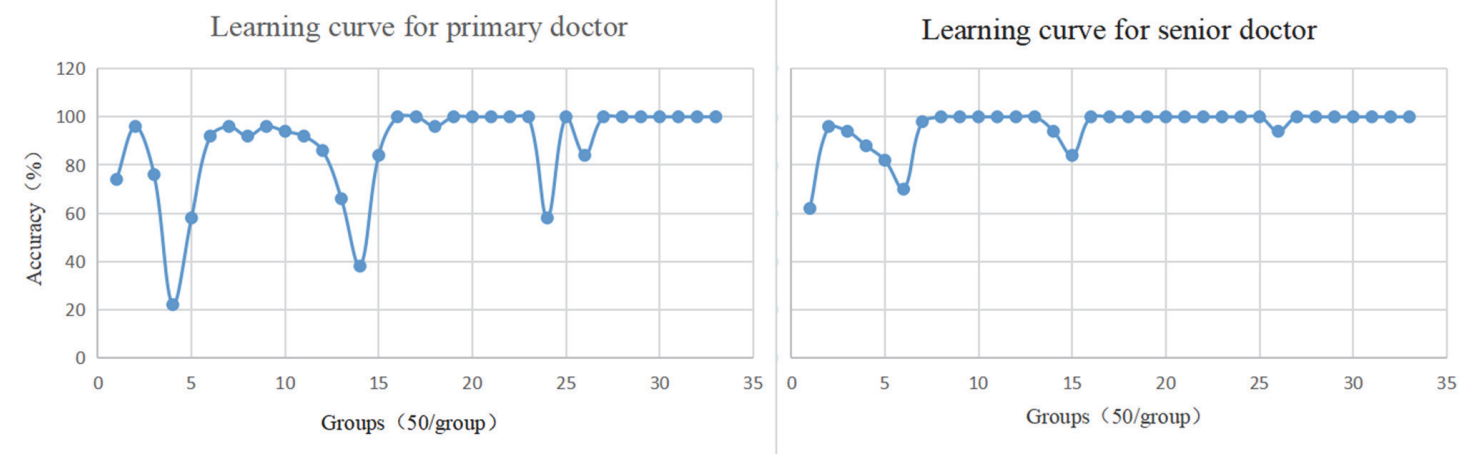

Abstract IDDF2021-ABS-0082 Figure 1

Abstract IDDF2021-ABS-0082 Table 1 Accuracy of NICE for primary and senior doctors

\begin{tabular}{llllllll}
\hline \multicolumn{3}{c}{ Primary doctor } & \multicolumn{5}{c}{ Senior doctor } \\
\hline Type & $\begin{array}{l}\text { Correct } \\
\text { Number }\end{array}$ & $\begin{array}{l}\text { Wrong } \\
\text { number }\end{array}$ & accuracy & $\begin{array}{l}\text { Correct } \\
\text { number }\end{array}$ & $\begin{array}{l}\text { Wrong } \\
\text { number }\end{array}$ & accuracy & $\chi^{2}$ \\
\hline Normal & 933 & 50 & 0.949 & 982 & 1 & 0.999 & 48.332 \\
Type1 & 208 & 30 & 0.874 & 200 & 38 & 0.840 & 1.098 \\
Type2 & 204 & 119 & 0.632 & 293 & 30 & 0.907 & 0.099 \\
Type3 & 129 & 1 & 0.992 & 130 & 0 & 1.000 & $0^{1}$ \\
Total & 1474 & 200 & 0.880 & 1605 & 69 & 0.958 & $1^{1}$ \\
\hline
\end{tabular}

('Pearson's chi-square test; ${ }^{2}$ Continuity correction for chi-square test) 